\title{
Circulating progesterone concentrations in nonlactating Holstein cows during reuse of intravaginal progesterone implants sanitized by autoclave or chemical disinfection
}

\author{
L. F. Melo, ${ }^{*}$ P. L. J. Monteiro Jr., ${ }^{*}$ L. H. Oliveira, ${ }^{*}$ M. M. Guardieiro,† J. N. Drum, ${ }^{*}$ M. C. Wiltbank, \\ and R. Sartori ${ }^{* 1}$ \\ *Department of Animal Science, University of São Paulo, Piracicaba, SP 13418-900 Brazil \\ †National Agricultural Laboratory, Ministry of Agriculture, Livestock and Food Supply, Campinas, SP 13100-105, Brazil \\ ‡Department of Dairy Science, University of Wisconsin-Madison, Madison 53706
}

\begin{abstract}
The aim of this study was to compare plasma progesterone $(\mathrm{P} 4)$ concentrations in nonlactating, multiparous Holstein cows $(\mathrm{n}=24)$ treated with 2 types of intravaginal implants containing either 1.0 or $1.9 \mathrm{~g}$ of $\mathrm{P} 4$ either at the first use or during reuse of the implants after sanitizing the implant by autoclave or chemical disinfection. In a completely randomized design with a $2 \times 3$ factorial arrangement and 2 replicates, every cow underwent 2 of 6 treatments. Two sources of P4 [controlled internal drug release (1.9 g of P4) from Zoetis (São Paulo, Brazil), and Sincrogest (1.0 g of P4) from Ourofino (Cravinhos, Brazil)] and 3 types of processing, new $(\mathrm{N})$, reused after autoclave (RA), and reused after chemical disinfection (RC), were used. After inducing luteolysis to avoid endogenous circulating $\mathrm{P} 4$, the cows were randomized in 1 of 6 treatments $(1.9 \mathrm{~g}$ of N, $1.9 \mathrm{~g}$ of RA, $1.9 \mathrm{~g}$ of RC, $1.0 \mathrm{~g}$ of N, $1.0 \mathrm{~g}$ of RA, and $1.0 \mathrm{~g}$ $\mathrm{RC})$. Cows were treated with the implants for $8 \mathrm{~d}$ and during this period blood samples were collected at 0 , 2, 12, 24, 48, 72, 96, 120, 144, 168, and 192 h. Statistical analyses were performed using Proc-Mixed and the mean \pm standard error of the mean $\mathrm{P} 4$ concentrations were calculated using the Proc-Means procedures of SAS 9.4 (SAS Institute Inc., Cary, NC). No interaction between treatments was observed. Comparing types of implant, average $\mathrm{P} 4$ concentrations during treatments were greater for $1.9 \mathrm{~g}$ than $1.0 \mathrm{~g}$ (1.46 vs. $1.14 \pm 0.04$ $\mathrm{ng} / \mathrm{mL}$ ). When types of processing were compared, average P4 concentrations did not differ between autoclaved and new inserts (1.46 vs. $1.37 \pm 0.05 \mathrm{ng} / \mathrm{mL}$; respectively), but both were greater than chemically disinfected implants $(1.09 \pm 0.04 \mathrm{ng} / \mathrm{mL})$. Within $1.9-\mathrm{g}$ P4 inserts, P4 concentrations from autoclaved implants
\end{abstract}

Received July 25, 2017.

Accepted December 5, 2017.

${ }^{1}$ Corresponding author: robertosartori@usp.br were greater than new, which were greater than chemically disinfected $(1.67 \pm 0.06$ vs. $1.49 \pm 0.07$ vs. 1.21 $\pm 0.05 \mathrm{ng} / \mathrm{mL}$; respectively). For 1.0-g P4 implants, $\mathrm{P} 4$ concentrations from autoclaved did not differ from new, but both were greater than chemically disinfected $(1.20 \pm 0.08$ vs. $1.24 \pm 0.06$ vs. $0.97 \pm 0.05 \mathrm{ng} / \mathrm{mL}$; respectively). In conclusion, the mean plasma $\mathrm{P} 4$ concentration in nonlactating Holstein cows was greater for 1.9 than $1.0 \mathrm{~g}$ of $\mathrm{P} 4$ and regardless of the type of implant, the autoclaving process provided greater circulating $\mathrm{P} 4$ in relation to chemical disinfection, and similar or greater $\mathrm{P} 4$ concentrations compared with a new implant.

Key words: hormone, disinfection, device, Bos taurus

\section{INTRODUCTION}

Intravaginal progesterone (P4) inserts were initially developed to treat anovular heifers and cows in seasonally calving New Zealand herds with smaller cows with much lower milk production, and luteal phase circulating P4 concentrations could be achieved (Macmillan et al., 1991; Macmillan and Peterson, 1993). However, more recent studies have used these intravaginal P4 implants in high-producing dairy cattle and in whole-herd synchronization programs, with much lower circulating P4 concentrations being achieved (Rabiee et al., 2002a; Gümen and Wiltbank, 2005; Zuluaga and Williams, 2008; Bisinotto et al., 2013). In anovular cows, 2 intravaginal implants, rather than only 1 , are required to achieve sufficient circulating $\mathrm{P} 4$ and normal fertility (Padula and Macmillan, 2006; Bisinotto et al., 2013; Pereira et al., 2017a,b). Several types of intravaginal P4 inserts are commercially available worldwide, with designs that allow retention within the vagina, usually with a T-shape, and prolonged delivery of P4, usually from $\mathrm{P} 4$-impregnated silicone molded over a nylon spine. In nonlactating ovariectomized cows, P4 inserts that have a similar surface area but contain 1.34 versus 
$1.9 \mathrm{~g}$ of $\mathrm{P} 4$ release a similar amount of $\mathrm{P} 4$, on average, 620 and $610 \mathrm{mg}$ of $\mathrm{P} 4$, respectively, over a period of 7 d (Rathbone et al., 2002). These treatments produced circulating $\mathrm{P} 4$ of $\sim 4 \mathrm{ng} / \mathrm{mL}$ on the day after insertion, with concentrations at $\sim 2.5 \mathrm{ng} / \mathrm{mL}$ by $7 \mathrm{~d}$ after insertion and few differences due to P4 load (10 to 30\% wt/wt; P4:silicone) or presence of additives (liquid paraffin, arachis oil, or polyethylene glycol), as long as surface area was kept constant (Rathbone et al., 2002). However, increasing surface area of silicone available for release of $\mathrm{P} 4$ produced a linear increase in circulating $\mathrm{P} 4$, indicating the fundamental nature of this aspect of insert design. In anovular high-producing dairy cows, use of a single, new intravaginal P4 insert containing $1.34 \mathrm{~g}$ of $\mathrm{P} 4$ increased circulating $\mathrm{P} 4$ to only 0.8 to 1.0 ng/mL (Cerri et al., 2009; Lima et al., 2009), probably due to the greater P4 metabolism in lactating dairy cows related to elevated liver blood flow (Wiltbank et al., 2006). Thus, surface area for release of P4 and physiology of treated cows seem to be major determinants of the circulating $\mathrm{P} 4$ concentrations produced by treatment with $\mathrm{P} 4$ inserts.

In many countries, the reuse of intravaginal inserts is a common method to reduce costs of synchronization programs, although not recommended by manufacturers. For example, treatment of cows with a 1.9-g P4 insert for $7 \mathrm{~d}$ only removes $\sim 600 \mathrm{mg}$ of $\mathrm{P} 4$, leaving $\sim 1.3 \mathrm{~g}$ of residual P4 load (Macmillan et al., 1991; Macmillan and Peterson, 1993; Rathbone et al., 2002). However, disinfection of the inserts before reuse is a major consideration, with producers primarily using either chemical disinfection of inserts or high-pressure steam sterilization using an autoclave (Zuluaga and Williams, 2008; Cerri et al., 2009; Long et al., 2009). Oral communication of results with reused P4 implants have been discussed in the scientific community, but publication of these results has generally not occurred due to concern from the manufacturer that off-label use could adversely affect product efficacy, product registrations with governmental agencies, or product sales. Thus, the P4 profiles have not been extensively evaluated in the scientific literature or directly compared following these 2 methods of disinfection before reuse of different intravaginal P4 implants containing different amounts of $\mathrm{P} 4$ in cattle.

Therefore, the objective of this experiment was to compare plasma $\mathrm{P} 4$ concentrations in cyclic nonlactating Holstein cows during use and reuse of intravaginal $\mathrm{P} 4$ inserts that originally contained 1.9 or $1.0 \mathrm{~g}$ of $\mathrm{P} 4$. Thus, along with evaluating the circulating $\mathrm{P} 4$ concentrations during use of implants with different P4 loads, we also evaluated whether circulating $\mathrm{P} 4$ would differ during reuse of the implants that were sanitized by 2 very different methods, using a high-pressure and -tem- perature autoclave or by chemical disinfection. The hypotheses for this experiment were that (1) plasma P4 concentrations during use of a new $1.9-\mathrm{g}$ intravaginal P4 implant would be similar to the profile for a new 1.0-g intravaginal P4 implant; 2) independent of method of disinfection, plasma $\mathrm{P} 4$ concentrations during treatment with a reused implant would be greater for a 1.9-g implant compared with a 1.0-g implant; and (3) independent of type of implant, plasma P4 concentrations would be greater for an autoclaved reused implant than for a chemically disinfected reused implant, based on data from other studies (Cerri et al., 2009; Long et al., 2009).

\section{MATERIALS AND METHODS}

This experiment was conducted at the Department of Animal Science facilities at Escola Superior de Agricultura "Luiz de Queiroz"/University of São Paulo, located in Piracicaba city, São Paulo, Brazil. The Animal Research Ethics Committee of Escola Superior de Agricultura "Luiz de Queiroz"/University of São Paulo approved all procedures involving cows in this study.

For this study, 24 nonlactating multiparous cycling Holstein cows were used. At the beginning of the experiment, cows averaged $600 \mathrm{~kg}$ of BW and a BCS of 3 (Ferguson et al., 1994). Cows were kept in confinement with free access to water and mineral salt, and were fed a TMR maintenance diet (NRC, 2001) based on sugar cane bagasse as forage and concentrate based on corn and soybean meal, minerals, and vitamins.

Cows were randomly assigned to 1 of 6 treatment groups using a completely randomized design with a $2 \times 3$ factorial arrangement of treatments and 2 replicates, and every cow underwent 2 treatments. We used 2 sources of intravaginal P4 implants [controlled internal drug release (1.9 g) from Zoetis (São Paulo, Brazil), and Sincrogest (1.0 g) from Ourofino (Cravinhos, Brazil)] and 3 types of processing [new $(\mathbf{N})$, reused autoclaved (RA), and reused chemically disinfected (RC)], resulting in the treatments $1.9 \mathrm{~g} \mathrm{~N}, 1.9 \mathrm{~g} \mathrm{RA}$, $1.9 \mathrm{~g} \mathrm{RC}, 1.0 \mathrm{~g} \mathrm{~N}, 1.0 \mathrm{~g} \mathrm{RA}$, and $1.0 \mathrm{~g}$ RC.

At the beginning of the experiment (d 0 ), each cow had its estrous cycle synchronized with a new 1.9-g P4 implant that remained for $8 \mathrm{~d}$. At 7 and $8 \mathrm{~d}$ after implant insertion, $25 \mathrm{mg}$ of dinoprost tromethamine $\left(\mathrm{PGF}_{2 \alpha}\right.$; Lutalyse, Zoetis) was administered, and on $\mathrm{d}$ 8 , after the withdrawal of the P4 implant, a Norgestomet (Crestar; MSD, São Paulo, Brazil) ear implant was inserted, which was maintained for $48 \mathrm{~h}$ to avoid ovulation and allow for a complete drop in circulating P4. On d 10, cows were randomized to 1 of 6 treatments. The implants were left within the vagina for 8 $\mathrm{d}$ and during this period blood samples were collected 


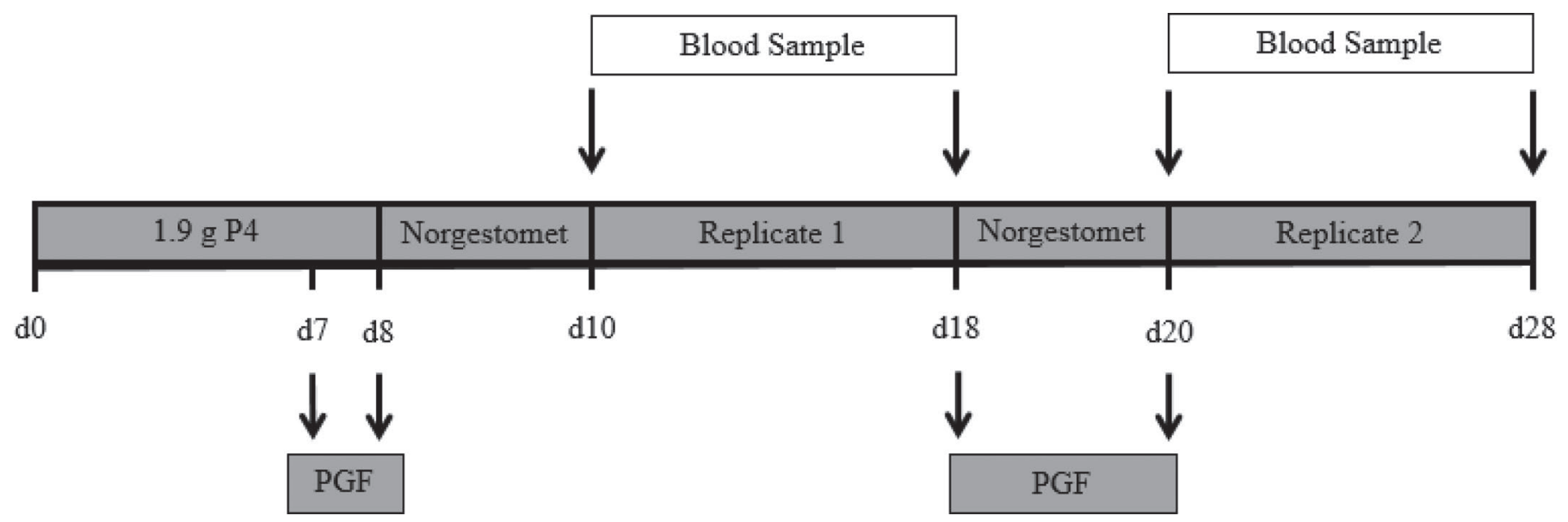

Figure 1. Diagram of activities for the study in 24 nonlactating dairy cows comparing plasma progesterone (P4) concentrations using a completely randomized block design with a $2 \times 3$ factorial arrangement of treatments and 2 replicates, with 2 intravaginal P4 implants $(1.9$ and $1.0 \mathrm{~g}$ ) and 3 types of processing [new $(\mathrm{N})$, reused autoclaved (RA), and reused chemically disinfected (RC)]. Day 0 is the beginning of the presynchronization protocol with cows receiving a new 1.9-g P4 implant, that remained for $8 \mathrm{~d}$, followed by 2 treatments of 25.0 mg of dinoprost tromethamine (PGF) on d 7 and 8. After P4 insert removal, a Norgestomet (Crestar; MSD, São Paulo, Brazil) ear implant was inserted for 2 d. After Norgestomet implant removal on d 10, the first replicate began and cows were randomly assigned to receive 1 of 6 treatments (1.9 g N, 1.9 g RA, $1.9 \mathrm{~g} \mathrm{RC}, 1.0 \mathrm{~g} \mathrm{~N}, 1.0 \mathrm{~g}$ RA, or $1.0 \mathrm{~g} \mathrm{RC}$ ). During the replicate, blood samples were collected at times 0, 2, 12, 24, 48, 72, 96, 120, 144, 168, and $192 \mathrm{~h}$ for plasma $\mathrm{P} 4$ concentrations. At the end of the replicate on d 18, implants were removed and another Norgestomet ear implant was inserted, remaining for $2 \mathrm{~d}$ and followed by a PGF treatment. On d 20, after Norgestomet removal, cows were treated again with PGF, and the second replicate began, similar to the first, with cows enrolled in a different treatment.

for circulating P4 measurements at $0,2,12,24,48,72$, 96, 120, 144, 168, and $192 \mathrm{~h}$. On the last day, after the last blood sampling, P4 implants were removed and Norgestomet was inserted again and maintained for 48 $\mathrm{h}$, together with other $\mathrm{PGF}_{2 \alpha}$ treatments at insertion and withdrawal times. Then, another replicate began on d 20, similar to the first replicate (Figure 1) but with cows randomly assigned to another treatment.

The autoclaved and chemically disinfected implants were previously used in lactating dairy cows for $8 \mathrm{~d}$. After removal, the inserts were washed in clean running water, and air-dried at room temperature. Prior to use in the experiment, the inserts were autoclaved or chemically disinfected. The protocol used to autoclave the P4 implants was similar to the one described by Cerri et al. (2009). Briefly, the inserts were placed in autoclave bags and autoclaved for $15 \mathrm{~min}$ at $121^{\circ} \mathrm{C}$ and $725 \mathrm{mmHg}$. For disinfection, the implants were dipped for $15 \mathrm{~min}$ in 1:2,000 diluted quaternary ammonia (CB30 TA; Ourofino) and air-dried at room temperature.

Blood samples were collected by puncture of the jugular vein into 10-mL heparinized evacuated tubes (Vacutainer; Becton Dickinson, Franklin Lakes, NJ) for plasma P4 measurements at $0,2,12,24,48,72,96$, 120, 144, 168, and $192 \mathrm{~h}$. Blood samples at $0 \mathrm{~h}$ were collected immediately before administration of treatments in both replicates on d 10 and 20, respectively, and at $192 \mathrm{~h}$ immediately before implant withdrawal. After collection, samples were placed in ice and trans- ported to the laboratory within $2 \mathrm{~h}$. Blood tubes were centrifuged at $1,900 \times g$ for $15 \mathrm{~min}$ at $4^{\circ} \mathrm{C}$ and plasma was frozen at $-20^{\circ} \mathrm{C}$. Plasma was analyzed for $\mathrm{P} 4$ by a solid-phase RIA using a commercial kit (Coat-A-Count; Siemens Healthcare Diagnostic, Los Angeles, CA). A single assay was performed with all samples. The assay sensitivity was $0.01 \mathrm{ng} / \mathrm{mL}$ and intra-assay coefficient of variation was $4.6 \%$.

Data were tested for homogeneity of variances and normality of residuals using the GLM procedure of SAS version 9.4 (SAS/STAT, SAS Institute Inc., Cary, NC). Homogeneity of variances followed Hovtest and Welsh methods, and normality of residuals were analyzed using the UNIVARIATE procedure of SAS following the Shapiro-Wilk method.

Concentrations of $\mathrm{P} 4$ were analyzed as repeated measures using the MIXED Procedure of SAS. The replicate was considered a random effect and cow within time was the subject effect. The fixed effects of type of implant (1.9 vs. 1.0), type of processing (new, $\mathrm{RA}$, or RC), time, and specific interactions of time with treatments were included in the model, fitting a Kenward-Roger method to calculate the denominator degrees of freedom to approximate the F-tests in the mixed models.

The estimates were calculated to generate the $P$ values from the adjusted Tukey comparisons of means, although the results are expressed as mean \pm standard error of means. Differences were considered significant 
Table 1. Plasma progesterone (P4) concentrations (mean \pm SEM) between 24 and $192 \mathrm{~h}$ during the $8 \mathrm{~d}$ of treatments in 24 nonlactating dairy cows after insertion of intravaginal P4 implants $(1.9 \mathrm{~g}$ or $1.0 \mathrm{~g})$ that were submitted to 3 types of processing [new $(\mathrm{N})$, reused autoclaved (RA), or reused chemically disinfected (RC)]; every cow underwent 2 treatments

\begin{tabular}{lcccc}
\hline P4 implant & $1.9 \mathrm{~g}$ & $1.0 \mathrm{~g}$ & $P$-value & Average \\
\hline $\mathrm{N}$ & $1.49 \pm 0.07^{\mathrm{b}}$ & $1.24 \pm 0.06^{\mathrm{a}}$ & 0.04 & $1.37 \pm 0.05^{\mathrm{a}}$ \\
$\mathrm{RA}$ & $1.67 \pm 0.06^{\mathrm{a}}$ & $1.20 \pm 0.08^{\mathrm{a}}$ & $<0.01$ & $1.46 \pm 0.05^{\mathrm{a}}$ \\
$\mathrm{RC}$ & $1.21 \pm 0.05^{\mathrm{c}}$ & $0.97 \pm 0.05^{\mathrm{b}}$ & 0.02 & $1.09 \pm 0.04^{\mathrm{b}}$ \\
$P$-value & $<0.05$ & $<0.01$ & - & $<0.01$ \\
Average & $1.46 \pm 0.04$ & $1.14 \pm 0.04$ & $<0.01$ & - \\
\hline
\end{tabular}

${ }^{\mathrm{a}-\mathrm{C}}$ Values in the same column with different supersripts differ $(P \leq 0.05)$.

when $P \leq 0.05$, whereas a tendency was defined as 0.10 $\geq P>0.05$.

\section{RESULTS AND DISCUSSION}

Although no interaction was detected between type of implant and type of preparation method $(P=0.19)$, clear differences were found between the types of implant (1.0 vs. 1.9 g P $4 ; P=0.0002$ ), implant preparation (RA vs. RC; $P<0.0001)$, and time $(P<0.0001)$ on circulating $\mathrm{P} 4$ concentrations. In addition, interactions on $\mathrm{P} 4$ concentrations were detected between types of implant and time $(P=0.05)$ and implant preparation method and time $(P=0.0002)$. Mean $\mathrm{P} 4$ concentration was greater for the 1.9-g P4 than 1.0-g P4 implant and lower for the chemically disinfected than the autoclaved implant during the $8 \mathrm{~d}$ of treatments (Table 1).

Our first hypothesis, that plasma P4 concentrations during the use of 2 new intravaginal implants containing 1.9 and $1.0 \mathrm{~g}$ of $\mathrm{P} 4$ would be similar, was based on the concept that when new inserts with similar surface area are used, even with different P4 loads, they are bioequivalent, having the same overall daily release of P4 during the first week of treatment $(\sim 0.61 \mathrm{~g}$; Rathbone et al., 2002). This hypothesis was rejected because the new 1.9-g P4 implant had $20.2 \%$ greater $(P=0.04)$ circulating $\mathrm{P} 4$ concentrations compared with the new 1.0-g P4 implant. Nevertheless, the repeated measures analysis (Figure 2A) did not detect differences at specific times during the $8 \mathrm{~d}$ of treatment with new 1.9- versus $1.0-\mathrm{g}$ P4 implants $(P>0.10)$. In addition, we found no difference between 1.9- versus 1.0-g P4 implants during the first $4 \mathrm{~d}$ (combined analysis; $P>$ $0.10)$ or the last $4 \mathrm{~d}$ of treatment $(P>0.10)$, although a decrease in $\mathrm{P} 4$ occurred during the last $4 \mathrm{~d}$ compared with first $4 \mathrm{~d}$ of treatment irrespective of $\mathrm{P} 4$ load in implant $(P<0.0001$; Figure $2 \mathrm{~A})$.

Our results contrast, somewhat, with other results that show that P4 implants with different P4 load but similar surface area produced similar circulating $\mathrm{P} 4$ concentrations during the first week of implant treatment (Rathbone et al., 2002). In contrast, residual P4 left in the implant after the first $7 \mathrm{~d}$ of treatment has been shown to be distinctly related to the initial amount of $\mathrm{P} 4$ in the new implant. For example, Macmillan and Peterson (1993) showed a quadratic relationship between the initial and residual amount of $\mathrm{P} 4$ over an insertion period of $15 \mathrm{~d}\left(\mathrm{R}^{2}=0.953\right)$. An implant containing $0.69 \mathrm{~g}$ of $\mathrm{P} 4$ was almost completely depleted of P4 (0.07 g of residual P4), whereas implants with $1.25,1.86$, and $2.67 \mathrm{~g}$ of $\mathrm{P} 4$ lost $\sim 1.0 \mathrm{~g}$ of $\mathrm{P} 4$ during the insertion period, leaving dramatically different residual $\mathrm{P} 4$ in the used implants $(0.31,0.80$, and $1.39 \mathrm{~g}$ of $\mathrm{P} 4$, respectively). Nevertheless, these previous release rate experiments were done with new P4 implants; the situation may be very different with a reused $\mathrm{P} 4$ implant, particularly after the changes in $\mathrm{P} 4$ distribution that could occur after the high pressure and heat involved in the autoclave process. One additional factor is that cows with widely varying feed intake and physiology had similar P4 release from a 1.9-g P4 implant during $11 \mathrm{~d}$ and similar residual $\mathrm{P} 4$ left in the implant after use for $11 \mathrm{~d}$ (Rabiee et al., 2001a,b).

In our experiment, we did not evaluate the residual $\mathrm{P} 4$ but would expect $\sim 0.4 \mathrm{~g}$ of $\mathrm{P} 4$ to be released during the first 4-d period from either 1.0- or 1.9-g P4 implants and 0.25 to $0.3 \mathrm{~g}$ of $\mathrm{P} 4$ released during the next $4 \mathrm{~d}$, based on previous results (Rabiee et al., 2001a,b, 2002b; Rathbone et al., 2002). Thus, our first hypothesis was rejected due to small, but significant, differences in $\mathrm{P} 4$ profiles during use of new $\mathrm{P} 4$ implants with differing initial $\mathrm{P} 4$ loads. In addition, the residual P4 amounts would be expected to be substantially different for 1.9-g $(\sim 1.2 \mathrm{~g} \mathrm{P} 4)$ compared with $1.0 \mathrm{-g}(\sim 0.4$ g P4) P4 implants when the implants were going to be reused for the second time in this experiment. Still, the successful reuse of the P4 implants in this experiment, as reflected in the $\mathrm{P} 4$ profiles during treatment of cows with reused P4 implants, should not be interpreted to mean that all types of $\mathrm{P} 4$ implants, regardless of initial $\mathrm{P} 4$ load or release rate, can be successfully used in all types of physiological situations.

Our second hypothesis was that, irrespective of disinfection method, the reused implant from the initial 

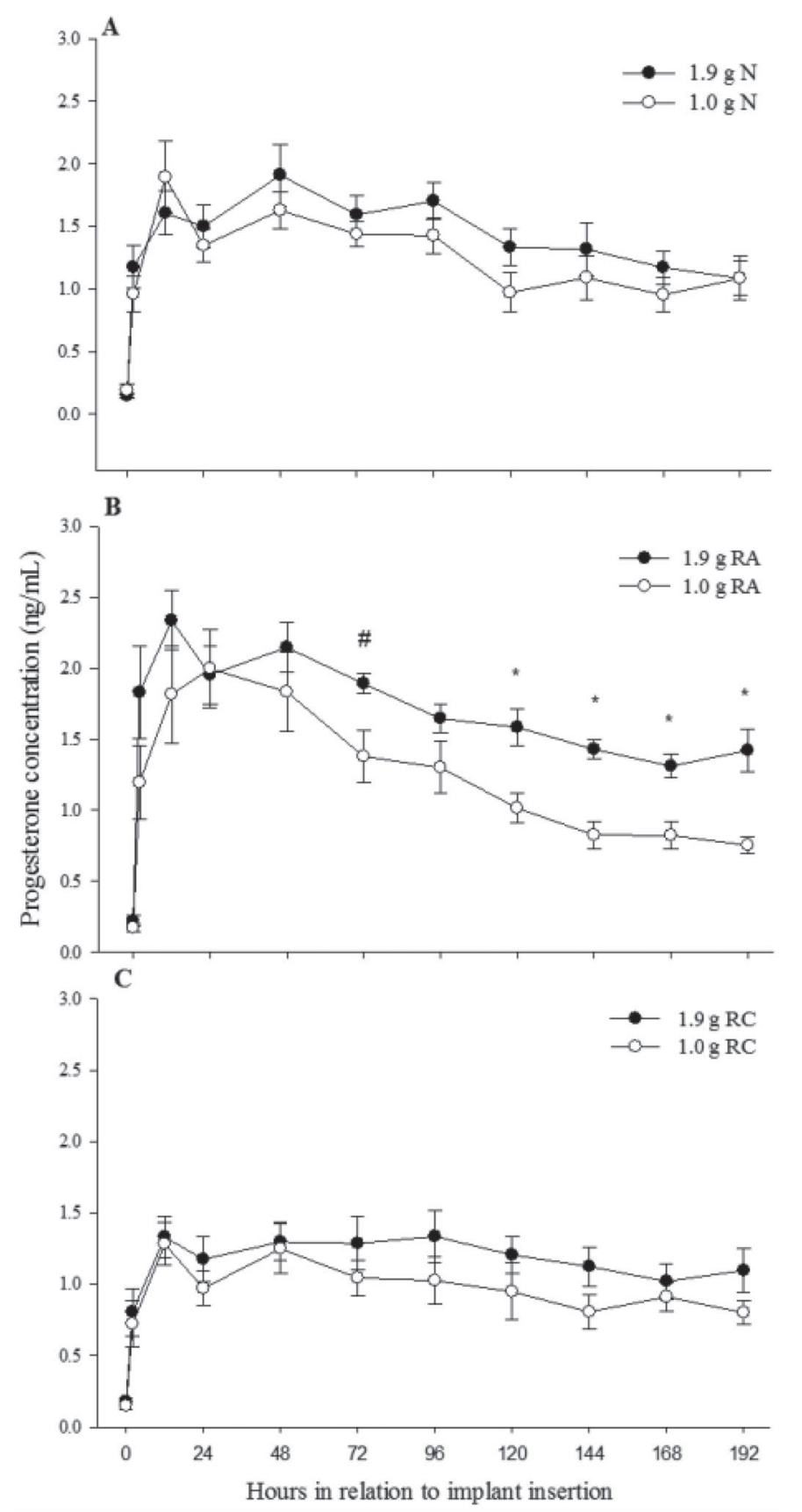

Figure 2. Plasma progesterone ( $\mathrm{P} 4)$ concentrations (mean $\pm \mathrm{SEM}$ ) during the $8 \mathrm{~d}$ of treatments in 24 nonlactating dairy cows using intravaginal P4 implants (1.9 or $1.0 \mathrm{~g}$ ) that were submitted to 3 types of processing [new $(\mathrm{N})$, reused autoclaved $(\mathrm{RA})$, or reused chemically disinfected $(\mathrm{RC})]$. Every cow underwent 2 treatments with effects of implant $(P=0.0002)$; processing $(P<0.0001)$; time $(P<0.0001)$; interaction between implant and processing $(P=0.19)$; interaction between implant and time $(P=0.05)$; and interaction between processing and time $(P=0.0002)$. (A) Plasma $\mathrm{P} 4$ concentrations from new intravaginal implants containing 1.9 versus $1.0 \mathrm{~g}$ of $\mathrm{P} 4$. (B) Plasma P4 concentrations from $8 \mathrm{~d}$ used autoclaved implants containing 1.9 versus $1.0 \mathrm{~g}$ of $\mathrm{P} 4$; a pound sign $(\#)$ at time $72 \mathrm{~h}$ represents a tendency to differ $(P=0.08)$, and an asterisk $(*)$ represents a difference $(P<$ 0.01). (C) Plasma P4 concentrations from $8 \mathrm{~d}$ used chemically disinfected intravaginal implants containing 1.9 versus $1.0 \mathrm{~g}$ of $\mathrm{P} 4$. 1.9-g P4 implant would produce greater circulating P4 than the reused 1.0-g implant. This was based on the assumption that much greater residual $\mathrm{P} 4$ would be available for release during reuse of the 1.9-g compared with the 1.0-g P4 implant. This hypothesis was fully supported by the data for the reused implants. Mean P4 concentrations during the full 8-d period were $39.2 \%$ greater $(P<0.01)$ for autoclaved 1.9 - versus 1.0 -g $\mathrm{P} 4$ implants and $24.7 \%$ greater for chemically disinfected 1.9- versus 1.0-g P4 implants (Table 1). This difference between 1.9- and 1.0-g P4 implants was most readily detected in cows treated with the autoclaved implants (Figure 2B), but was not detected using the repeated measures analysis of daily evaluations in cows treated with chemically disinfected implants (Figure 2C). It appears that autoclaving the implant caused more of the residual $\mathrm{P} 4$ to be releasable during the reuse period for both 1.9- and 1.0-g P4 implants (RA vs. RC). However, the differences between the 1.9-g RA compared with 1.0-g RA implants at all times after $96 \mathrm{~h}$ (Figure 2B) indicates an earlier depletion of residual $\mathrm{P} 4$ from the 1.0- versus 1.9 -g RA implant. In the reused implants, the initial large increase in circulating $\mathrm{P} 4$ concentrations that was observed with autoclaved implants did not occur with chemically disinfected implants, but the profile remained relatively flat throughout the 8-d period, possibly indicating a slower exhaustion of the residual $\mathrm{P} 4$, particularly with the $1.0-\mathrm{g}$ P4 implant (Figure 2C).

Previous studies have described the $\mathrm{P} 4$ profiles using implants with differing $\mathrm{P} 4$ loads but similar surface area in bilaterally ovariectomized nonlactating cows (Rathbone et al., 2002), or when new or used intravaginal P4 implants were used in bilaterally ovariectomized nonlactating cows (Zuluaga and Williams, 2008) or in high-producing dairy cows (Cerri et al., 2009). However, ours is the first comparison of new and reused implants with differing $\mathrm{P} 4$ loads that were sanitized by 2 different methods, autoclaving versus chemical disinfection. The autoclaving process may modify the structure of the implant or the location or disposition of P4 within the insert (Zuluaga and Williams, 2008). The increased elution of $\mathrm{P} 4$ caused by the autoclaving process may produce more rapid subsequent depletion of the remaining $\mathrm{P} 4$, leading to exhaustion of $\mathrm{P} 4$ in the 1.0-g but not the 1.9-g P4 implants. Nevertheless, in both previously used autoclaved implants, average $\mathrm{P} 4$ concentrations were generally greater than $1 \mathrm{ng} / \mathrm{mL}$ during the $8 \mathrm{~d}$ of treatment, which should be sufficient to prevent a GnRH-LH surge and may be sufficient to synchronize the emergence of a new follicular wave in some P4-based fixed time AI protocols (Baruselli et al., 2012; Wiltbank et al., 2014), although this will need to be rigorously examined in future experiments. 
Our third hypothesis was that circulating P4 would be greater for reused implants that were sanitized using an autoclave rather than chemical disinfection, based on previous reports with autoclaved P4 implants (Zuluaga and Williams, 2008). This hypothesis was accepted. The complete profiles for 1.9-g (Figure 3A) or 1.0-g (Figure 3B) P4 implants demonstrate the effectiveness of autoclaving in causing residual $\mathrm{P} 4$ release. The autoclaved 1.9-g P4 implant produced $38.0 \%$ greater circulating $\mathrm{P} 4$ than a chemically disinfected $1.9-\mathrm{g}$ P4 implant and even produced greater $\mathrm{P} 4$ concentrations $(12.1 \%)$ than a new implant (Table 1). Similarly, the autoclaved 1.0-g P4 implant produced $23.7 \%$ greater circulating P4 than a chemically disinfected 1.0-g P4 implant, although we found no difference between new and autoclaved 1.0-g P4 implants (Table 1). Figure 4 demonstrates the differences in circulating P4 during the first $4 \mathrm{~d}$ ( 24 to $96 \mathrm{~h}$ ) compared with the last $4 \mathrm{~d}$ (120 to $192 \mathrm{~h}$ ) of treatment with reused 1.9- versus 1.0-g P4 implants that were previously autoclaved or chemically disinfected. The autoclaved reused 1.9-g P4 implant produced the greatest $\mathrm{P} 4$ concentrations during the first $4 \mathrm{~d}$ of treatment $(1.83 \mathrm{ng} / \mathrm{mL}$, on average), and this decreased $21.3 \%$ during the last $4 \mathrm{~d}$ of treatment (1.44 $\mathrm{ng} / \mathrm{mL}$ ). In contrast, cows treated with the chemically disinfected 1.9-g P4 implant had no significant decrease in circulating $\mathrm{P} 4$ from the first 4 versus the last $4 \mathrm{~d}$ of treatment, but values were significantly lower in both periods for cows treated with a chemically disinfected versus autoclaved 1.9-g P4 implant (Figure 4). For the 1.0-g P4 implant, we noted a dramatic decrease in circulating P4 during the first 4 versus the last $4 \mathrm{~d}$ of treatment with an autoclaved implant (40.4\%), but also a smaller but significant decrease in circulating $\mathrm{P} 4$ between the first 4 and the last $4 \mathrm{~d}$ in cows treated with the chemically disinfected 1.0-g P4 implant (20.2\%). In summary, autoclaving compared with chemically disinfecting increased circulating $\mathrm{P} 4$ during both the first $4(32.2 \%)$ and the last $4 \mathrm{~d}(22.2 \%)$ of treatment with a 1.9-g P4 implant, but only during the first $4 \mathrm{~d}$ $(26.2 \%)$ and not during the last $4 \mathrm{~d}$ of treatment with the 1.0-g P4 implant (Figure 4). Thus, solely based on $\mathrm{P} 4$ profile, reuse of $\mathrm{P} 4$ implants seems suitable when sufficient residual $\mathrm{P} 4$ remains in the implant and the releasable $\mathrm{P} 4$ is optimized by autoclaving the implant before reuse.

One other important consideration is that for new and autoclaved P4 implants there is a consistent decrease in circulating $\mathrm{P} 4$ concentrations over time after implant insertion $(P<0.0001)$, as previously reported (Macmillan and Peterson, 1993; Cerri et al., 2009). It seems likely that most of the differences in $\mathrm{P} 4$ profiles observed in our study were related to alterations in $\mathrm{P} 4$ release from the implant, as the vaginal mucosa has high permeability to steroid hormones and P4 subsequently enters the capillaries and blood stream by passive diffu-
A

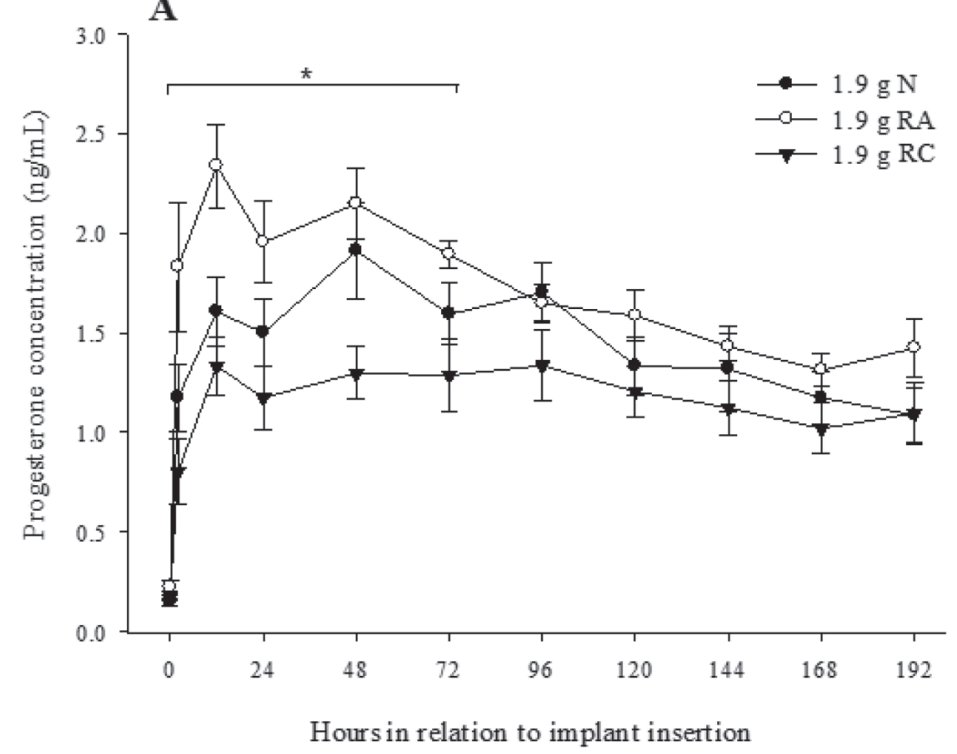

B

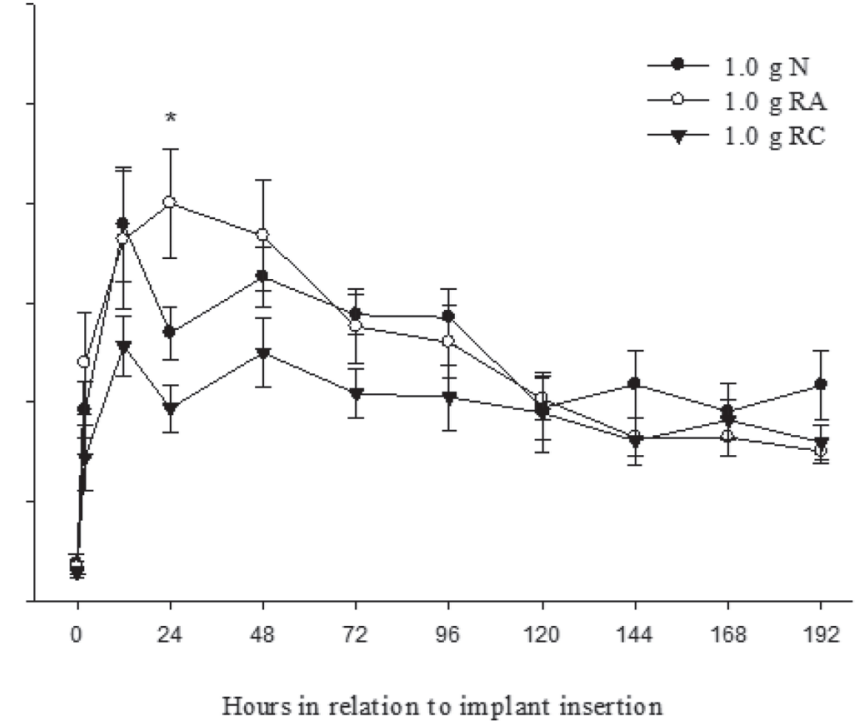

Figure 3. Plasma progesterone $(\mathrm{P} 4)$ concentrations (mean \pm SEM) during the $8 \mathrm{~d}$ of treatments with new $(\mathrm{N})$, reused autoclaved $(\mathrm{RA})$, or reused chemically disinfected $(\mathrm{RC})$ implants in 24 nonlactating dairy cows, with effects of implant $(P=0.0002)$; processing $(P<0.0001)$; time $(P<0.0001)$; interaction between implant and processing $(P=0.19)$; interaction between implant and time $(P=0.05)$; and interaction between processing and time $(P=0.0002)$. (A) Plasma P4 concentrations from 1.9-g intravaginal implants; an asterisk $(*)$ represents a difference $(P<$ $0.05)$ between RA and RC. (B) Plasma P4 concentrations from 1.0-g intravaginal implants; an asterisk $(*)$ represents a difference $(P<0.0001)$ between RA and RC. 


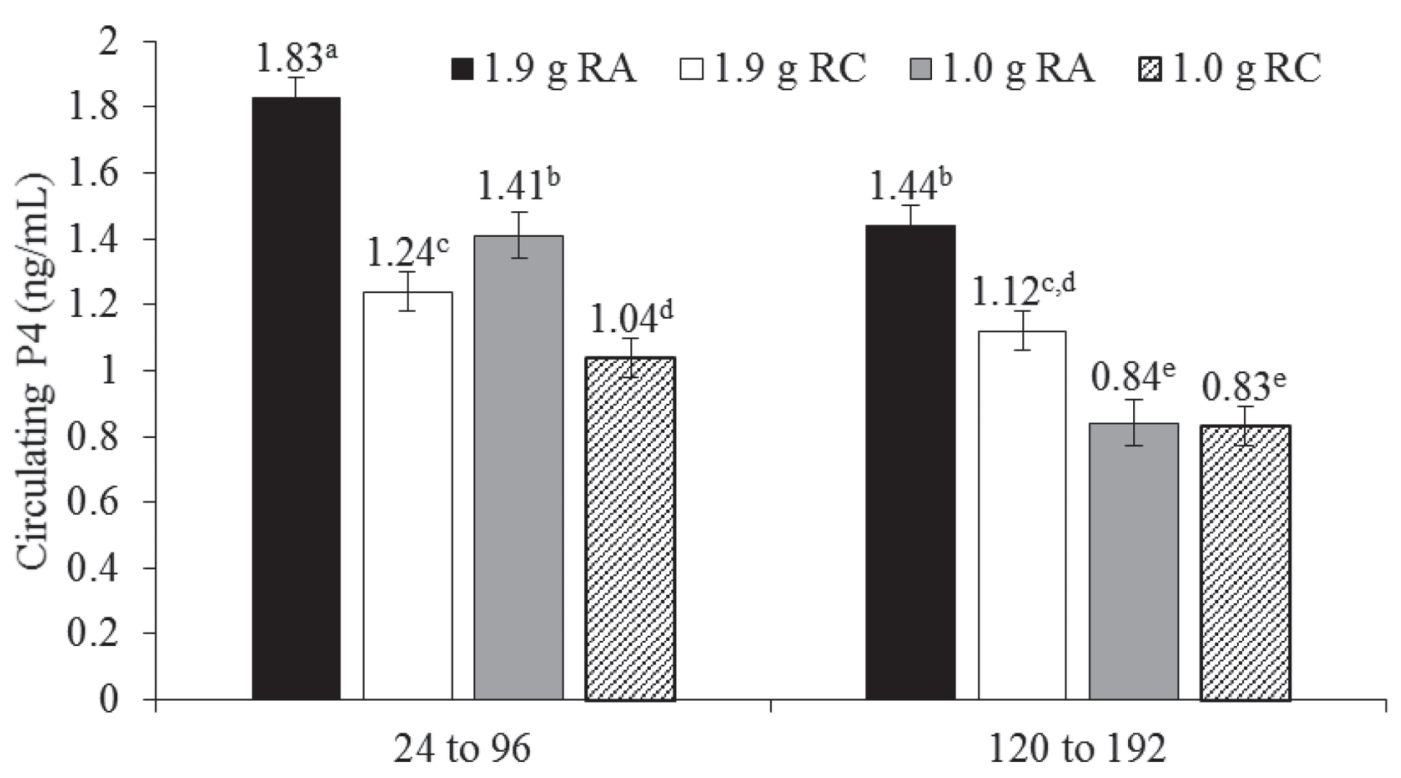

Hours after P4 device insertion

Figure 4. Plasma progesterone (P4) concentrations (mean $\pm \mathrm{SEM}$ ) during the $8 \mathrm{~d}$ of treatments with a reused $\mathrm{P} 4$ implant that was $1.9 \mathrm{~g}$ autoclaved (RA; $\mathrm{n}=8), 1.9 \mathrm{~g}$ chemically disinfected $(\mathrm{RC} ; \mathrm{n}=8), 1.0 \mathrm{~g} \mathrm{RA}(\mathrm{n}=8)$, or $1.0 \mathrm{~g} \mathrm{RC}(\mathrm{n}=8)$. Comparisons were done for the first $4 \mathrm{~d}$ and last $4 \mathrm{~d}$ after implant insertion, with effects of implant $(P<0.001)$; processing $(P<0.001)$; time $(P<0.0001)$; interaction between processing and time $(P<0.001)$; and interaction between implant, processing, and time $(P=0.01)$. Values with different letters $(\mathrm{a}-\mathrm{e})$ differ $(P \leq 0.05)$.

sion (Rothen-Weinhold et al., 2000). Indeed, P4 release from a silicone implant seems to follow a zero-order $\left(\mathrm{R}^{2}=0.989\right)$ release mechanism with particulate $\mathrm{P} 4$ in a saturating concentration at the interface of surfaces (Rathbone et al., 2002). In this regard, treatment with 1, 2, or $3 \mathrm{P} 4$ implants produced corresponding increases in circulating $\mathrm{P} 4(2 \times$ or $3 \times)$, with similar depletion of $\mathrm{P} 4$ from each of the implants, regardless of the number of implants present in the vagina or the circulating $\mathrm{P} 4$ concentration (Macmillan and Peterson, 1993). Nevertheless, differences in animal size (Cerri et al., 2009) and metabolic clearance rate for P4 (Sangsritavong et al., 2002) can potentially alter the circulating P4 achieved in different cows or different experimental situations.

\section{CONCLUSIONS}

Mean plasma P4 concentration in nonlactating Holstein cows was greater for 1.9-g than 1.0-g P4 implants. For previously used P4 implants, sanitizing the reused implant using an autoclave produced greater circulating $\mathrm{P} 4$ concentrations, compared with chemically disinfected implants, and similar or greater circulating P4 compared with new implants.

\section{ACKNOWLEDGMENTS}

Leonardo F. Melo was supported by a scholarship from the Coordination for the Improvement of Higher
Education Personnel (CAPES, Brasília, Brazil) of Brazil. Co-authors were supported by scholarships from the National Council for Scientific and Technological Development (CNPq, Brasília, Brazil) of Brazil and from the São Paulo Research Foundation (FAPESP, São Paulo, Brazil). This project was funded by grants from FAPESP (\#2011/11395-0) and CNPq (\#460902/20148).

\section{REFERENCES}

Baruselli, P. S., M. F. Sa, R. M. Ferreira, J. N. S. Sales, L. U. Gimenes, L. M. Vieira, M. F. Mendanha, and G. A. Bo. 2012. Manipulation of follicle development to ensure optimal oocyte quality and conception rates in cattle. Reprod. Domest. Anim. 47:134-141.

Bisinotto, R. S., E. S. Ribeiro, F. S. Lima, N. Martinez, L. F. Greco, L. Barbosa, P. P. Bueno, L. F. S. Scagion, W. W. Thatcher, and J. E. P. Santos. 2013. Targeted progesterone supplementation improves fertility in lactating dairy cows without a corpus luteum at the initiation of the timed artificial insemination protocol. J. Dairy Sci. 96:2214-2225.

Cerri, R. L. A., H. M. Rutigliano, R. G. S. Bruno, and J. E. P. Santos. 2009. Progesterone concentration, follicular development and induction of cyclicity in dairy cows receiving intravaginal progesterone inserts. Anim. Reprod. Sci. 110:56-70.

Ferguson, J. D., D. T. Galligan, and N. Thomsen. 1994. Principal descriptors of body condition score in Holstein cows. J. Dairy Sci. $77: 2695-2703$.

Gümen, A., and M. C. Wiltbank. 2005. Follicular cysts occur after a normal estradiol-induced GnRH/LH surge if the corpus hemorrhagicum is removed. Reproduction 129:737-745.

Lima, J. R., F. A. Rivera, C. D. Narciso, R. Oliveira, R. C. Chebel, and J. E. P. Santos. 2009. Effect of increasing amounts of supplemental progesterone in a timed artificial insemination protocol on fertility of lactating dairy cows. J. Dairy Sci. 92:5436-5446. 
Long, S. T., C. Yoshida, and T. Nakao. 2009. Plasma progesterone profile in ovariectomized beef cows after intra-vaginal insertion of new, once-used or twice-used CIDR. Reprod. Domest. Anim. 44:80-82.

Macmillan, K. L., and A. J. Peterson. 1993. A new intravaginal progesterone releasing device for cattle (CIDR-b) for estrous synchronization, increasing pregnancy rates and the treatment of postpartum anestrus. Anim. Reprod. Sci. 33:1-25.

Macmillan, K. L., V. K. Taufa, D. R. Barnes, and A. M. Day. 1991. Plasma progesterone concentrations in heifers and cows treated with a new intravaginal device. Anim. Reprod. Sci. 26:25-40.

NRC. 2001. Nutrient Requirements of Dairy Cattle. 7th rev. ed. Natl. Acad. Press, Washington, DC.

Padula, A. M., and K. L. Macmillan. 2006. Effect of treatment with two intravaginal inserts on the uterine and vaginal microflora of early postpartum beef cows. Aust. Vet. J. 84:204-208.

Pereira, M. H. C., C. P. Sanches, T. G. Guida, M. C. Wiltbank, and J. L. M. Vasconcelos. 2017a. Comparison of fertility following use of one versus two intravaginal progesterone inserts in dairy cows without a CL during a synchronization protocol before timed AI or timed embryo transfer. Theriogenology 89:72-78.

Pereira, M. H. C., M. C. Wiltbank, T. G. Guida, F. R. Lopes, and J. L. M. Vasconcelos. 2017b. Comparison of 2 protocols to increase circulating progesterone concentration before timed artificial insemination in lactating dairy cows with or without elevated body temperature. J. Dairy Sci. 100:8455-8470.

Rabiee, A. R., D. Dalley, J. M. Borman, K. L. Macmillan, and F. Schwarzenberger. 2002a. Progesterone clearance rate in lactating dairy cows with two levels of dry matter and metabolisable energy intakes. Anim. Reprod. Sci. 72:11-25.

Rabiee, A. R., K. L. Macmillan, and F. Schwarzenberger. 2001a. The effect of level of feed intake on progesterone clearance rate by measuring faecal progesterone metabolites in grazing dairy cows. Anim. Reprod. Sci. 67:205-214.
Rabiee, A. R., K. L. Macmillan, and F. Schwarzenberger. 2001b. Progesterone metabolism in ovariectomised non-lactating HolsteinFriesian cows treated with progesterone with two levels of feed intake. Anim. Reprod. Sci. 66:35-46.

Rabiee, A. R., K. L. Macmillan, and F. Schwarzenberger. 2002b. Plasma, milk and faecal progesterone concentrations during the oestrous cycle of lactating dairy cows with different milk yields. Anim. Reprod. Sci. 74:121-131.

Rathbone, M. J., C. R. Bunt, C. R. Ogle, S. Burggraaf, K. L. Macmillan, C. R. Burke, and K. L. Pickering. 2002. Reengineering of a commercially available bovine intravaginal insert (CIDR insert) containing progesterone. J. Control. Release 85:105-115.

Rothen-Weinhold, A., N. Oudry, K. Schwach-Abdellaoui, S. FrutigerHughes, G. J. Hughes, D. Jeannerat, U. Burger, K. Besseghir, and R. Gurny. 2000. Formation of peptide impurities in polyester matrices during implant manufacturing. Eur. J. Pharm. Biopharm. $49: 253-257$.

Sangsritavong, S., D. K. Combs, R. Sartori, L. E. Armentano, and M. C. Wiltbank. 2002. High feed intake increases liver blood flow and metabolism of progesterone and estradiol-17 beta in dairy cattle. J. Dairy Sci. 85:2831-2842.

Wiltbank, M., H. Lopez, R. Sartori, S. Sangsritavong, and A. Gumen. 2006. Changes in reproductive physiology of lactating dairy cows due to elevated steroid metabolism. Theriogenology 65:17-29.

Wiltbank, M. C., A. H. Souza, P. D. Carvalho, A. P. Cunha, J. O. Giordano, P. M. Fricke, G. M. Baez, and M. G. Diskin. 2014 Physiological and practical effects of progesterone on reproduction in dairy cattle. Animal 8:70-81.

Zuluaga, J. F., and G. L. Williams. 2008. High-pressure steam sterilization of previously used CIDR inserts enhances the magnitude of the acute increase in circulating progesterone after insertion in cows. Anim. Reprod. Sci. 107:30-35. 